\title{
Short communication: Early modification of the circadian organization of cow activity in relation to disease or estrus
}

\author{
Isabelle Veissier, ${ }^{*} \dagger^{1}$ Marie-Madeleine Mialon, ${ }^{*} \dagger$ and Karen Helle Sloth $\ddagger$ \\ *INRA, UMR1213 Herbivores, F-63122 Saint-Genès-Champanelle, France \\ †VetAgro Sup, Clermont Université, UMR1213 Herbivores, BP 10448, F-63000, Clermont-Ferrand, France \\ †GEA Farm Technologies GmbH, Nørsskovvej 1B, DK-8660 Skanderborg, Denmark
}

\section{ABSTRACT}

Biological rhythms are an essential regulator of life. There is evidence that circadian rhythm of activity is disrupted under chronic stress in animals and humans, and it may also be less marked during diseases. Here we investigated whether a detectable circadian rhythm of activity exists in dairy cows in commercial settings using a real-time positioning system. We used CowView (GEA Farm Technologies) to regularly record the individual positions of 350 cows in a Danish dairy farm over $5 \mathrm{mo}$ and to infer the cows' activity (resting, feeding, in alley). We ran a factorial correspondence analysis on the cows' activities and used the first component of this analysis to express the variations in activity. On this axis, the activities obtained the following weights: resting $=-0.15$; in alleys $=+0.12$; feeding $=+0.34$. By applying these weights to the proportions of time each cow spent on each of the 3 activities, we were able to chart a circadian rhythm of activity. We found that average level of activity of a cow on a given day and its variations during that day varied with specific states (i.e., estrus, lameness, mastitis). More specifically, circadian variations in activity appeared to be particularly sensitive and to vary 1 to $2 \mathrm{~d}$ before the farmer detected a disorder. These findings offer promising avenues for further research to design models to predict physiological or pathological states of cows from real-time positioning data.

Key words: dairy cow, animal health, precision livestock farming, behavioral rhythm

\section{Short Communication}

Biological rhythms are an essential regulator of life (Foster and Kreitzman, 2014; Smolensky et al., 2016). Diurnal animals are more active during the day whereas

Received August 9, 2016.

Accepted January 3, 2017.

${ }^{1}$ Corresponding author: isabelle.veissier@clermont.inra.fr nocturnal ones are more active at night, and this pattern is species-specific. Evidence exists that circadian rhythm of activity is disrupted under chronic stress in animals and humans. For instance, rodents (nocturnal species) show more activity during the daylight period and less during the dark period when they are submitted to repeated stressors or inescapable electrical shocks (Stewart et al., 1990; Solberg et al., 1999). The organization of activity also appears disrupted in calves under stress, which show less activity at night but more at the very beginning or end of the daylight period when submitted to social mixing (Veissier et al., 2001). In cattle, circadian variations of activity were found to be less marked $2 \mathrm{~d}$ before the occurrence of symptoms of pneumonia (Veissier et al., 1989). These results were obtained by coincidence during an experiment on the stabilization of activity rhythms after the cattle were turned from pasture to indoor conditions and during which an outbreak of pneumonia occurred. These findings were never subsequently confirmed, due to the heavy observational input required; however, today's precision livestock farming technologies can automatically measure several characteristics, including activity of the animals. Here we used a real-time locating system (RTLS) to infer cows' behavior in a commercial dairy herd for several months. First we tested whether we could detect a circadian rhythm of activity of the cows from the RTLS data. Then we investigated whether the average level of activity during the day or its circadian variations were disturbed before the farmer detected signs of disease and mentions it in farm records. If such a relation could be established, then RTLS could be used for an integrated management of animal health, helping to identify diseased animals at an early stage and, thus, make it possible to find an earlier cure (probably using less medicine) and limit the spread of disease in a herd by isolating the diseased animal.

We followed 350 dairy cows from a Danish producer for 5 mo. Measurements, diet manipulations, housing, and handling of the animals or any other environment or management factors were all part of the on-farm 
routine; thus, our observations did not require any intervention. The cows were either Danish Holstein (75\%) or Red Danish $(25 \%)$ that produced on average more than $10,000 \mathrm{~L}$ of milk/yr. The cows were kept indoors year round in a barn equipped with cubicles and an automatic milking system (AMS; with 6 milking robots, acquired in 2009; VMS, Delaval, Kolding, Denmark). The lights were on all day, but were reduced from 2200 to $0600 \mathrm{~h}$. The cows had to go through the AMS to move from the resting area (with cubicles) to the feeding area. The food (a mixed diet with grass silage, maize silage, soya and rapeseed meals, barley, palm oil, minerals, and molasses) was distributed at the feeding table between 0600 and $0730 \mathrm{~h}$, and a robot pushed the remaining food to the feeding table every 2 $\mathrm{h}$ from 0300 to $1700 \mathrm{~h}$. In addition, when at the AMS, the cows also received 1 to $6 \mathrm{~kg}$ of soya and barley (3.7 $\mathrm{kg}$ on average). The cows visited the AMS from 2 to 4 times a day. At 1000 and $1700 \mathrm{~h}$, an employee or the farmer cleaned the cubicles while cows that were late at milking were led to the AMS (especially young cows or cows with a low milk production, which are often less motivated to eat), and those that needed a specific management intervention were picked-up and treated accordingly (insemination or administration of a medical treatment). At 0600 and $2100 \mathrm{~h}$, an employee or the farmer walked among the cows for about $1 \mathrm{~h}$ and looked closely at the animals to detect estrus and health problems such as lameness. Signs used to detect estrus were standing to be mounted, mounting, and mucous and blood on the vulva. The time since last estrus and the cow reproductive status were used to confirm the interpretation of these signs. Cows were considered lame when their gait was affected with short striding on one or more limbs and an archedback posture while walking and standing [score 3 on the 1-5 lameness scale from Sprecher et al. (1997)]. Foot lesions could also be detected at claw trimming. In case of lameness or foot lesions, the cows were treated by pedicure or medication. Any sign detected during these 2 systematic visits was recorded and the list was updated if more cases were found between the 2 visits. Mastitis was detected from milk conductivity assessed by the AMS; an increase of more than $25 \%$ conductivity in the milk from one quarter compared with the cow conductivity average led to an alarm to the farmer, after which the farmer further checked the appearance of the udder and the presence of flakes in the milk. The farmer kept records of all events: interventions on the herd, estrus, lameness, mastitis, accident, calving, respiratory problems, diarrhea, and so on.

Lactating cows had been fitted with CowView tags (GEA Farm Technologies, Bönen, Germany) all at the same time, 10 mo before the observations were per- formed, from October 2013 to February 2014. Then new cows were tagged when they joined the lactating cow groups. The tag $(6 \times 4.5 \times 4 \mathrm{~cm}, 150 \mathrm{~g})$ was fixed on a collar and maintained on top on the cow neck thanks to a 400-g counterweight $(7 \times 5 \times 3 \mathrm{~cm})$. The tag emitted radio waves within the ultra-wide band area that were detected by several antennas mounted within the barn. Cow position was determined every second by triangulation with an accuracy of less than $50 \mathrm{~cm}$ deviance. The accuracy was checked by adding fixed tags, by which true position in the barn is known, and measuring the deviation between what is detected by CowView and the true position. Here we inferred cow activity from this position: if the cow was found in a cubicle, it was classified as resting, if the cow was within the feed bunk zone, it was classified as feeding, otherwise it was classified as in alleys. We used the hourly accumulated activities as determined by the CowView system (i.e., time spent resting, feeding, or in alleys during each hour of the day) for 5 mo. We used data from lactating cows only. The dry cows were accommodated separately and moved to a group of lactating cows during the week after calving. The lactating cows were accommodated in 4 production pens. There were 60 to 120 cows per pen and the space allowance was 7.4 to $7.5 \mathrm{~m}^{2} /$ cow.

We first calculated the time each cow spent in each activity (resting, feeding, in alleys) per day, plus the average and standard error across days. To determine activity levels and their variations during the day, we attributed a weight to each activity according to the method proposed by Veissier et al. (2001). The weights were obtained from factorial correspondence analysis, where the observations were the hours of the day and the variables were the number of scans (across all animals and days) when each activity was detected. Before performing the factorial correspondence analysis, we removed outlier days, defined as data from a specific day and animal when the frequency of an activity was outside the $95 \%$ confidence interval [i.e., that animal spent more (or less) time on a given activity than its average \pm 2 SE calculated over the previous $14 \mathrm{~d}$ ]. We assumed that this animal encountered a disorder on that outlier day (e.g., it was diseased or some disturbance occurred in the barn). On the first axis of the factorial correspondence analysis, which summarized $93 \%$ of the variability, the 3 activities obtained the following weights: resting $=-0.15$; in alleys $=+0.12$; feeding $=+0.34$. This axis was considered to express level of activity. For each cow and each day, we then calculated level of activity per hour by multiplying the percentage of time spent in each activity by the weight attributed to the activity. We also calculated the average level of activity during the day [i.e., during daytime (from 0800 to 2200 
h), when cows had the highest activity, and at night (from 2300 to $0700 \mathrm{~h}$ )] and the size of the circadian variations in activity level. The circadian variations were estimated by 2 indicators: the standard deviation between the level of activity across the hours of the day and the root mean square of successive differences (RMSSD), which estimates the variations in that level of activity from one hour to the next on, such as for the analysis of variations in the duration of successive heart beats (Task Force on HRV, 1996).

We then ran variance analyses to relate the average activity level of a cow on a given day and its circadian variations to the events recorded by the farmer. We discarded from this analysis the data from days when a disturbance occurred but could not be attributed to a disease: days when there had been a general disturbance in the barn (e.g., power or mechanical failure, claw trimming on all animals, in which case data from all cows were discarded) and data on a given animal when it suffered a specific intervention (e.g., removal of an ovarian cyst) or accident (e.g., abortion, in which case day of accident and the following $7 \mathrm{~d}$ were removed). We also removed the days after a disease was observed on an animal (d 1 to 7 after detection) to be able to distinguish days on which a disorder occurred (or the few days before) from control days when the animals were supposedly in good health. For this purpose, we ran 3 series of analyses comparing (1) days on which the farmer detected disease or estrus (referred to as d 0), (2) $1 \mathrm{~d}$ before the detection (referred to as $\mathrm{d}-1$ ), and (3) $2 \mathrm{~d}$ before detection (referred to as $\mathrm{d}-2$ ) against all other days considered as control days. We used the Proc Mixed procedure of SAS for repeated measurements across days with a Tukey adjustment (version 9, SAS Institute Inc., Cary, NC). The subjects were cows and the fixed factors were state of the animal (control day or disease/estrus), parity (lactation 1,2,3+), and DIM ( $<90 \mathrm{~d}$ after calving, 90-219 d after calving, from $220 \mathrm{~d}$ after calving to $61 \mathrm{~d}$ before next calving, from $60 \mathrm{~d}$ before to next calving). Although not the focus of this study, parity and DIM were included in the model because they are known to affect the feeding behavior of cows (Norring et al., 2014; Coletti, 2015). These 2 factors significantly affected the average activity level and its circadian variations $(P<0.001$ in all cases $)$ with, for example, younger cows and cows at the beginning or end of the lactation being more active; however, we did not comment on these findings further because they are not new and not the focus of the present study. Between-factor interactions were nonsignificant and thus excluded from the analyses. The data set included 297 cases of estrus, 206 lameness (202 cows were lame once and 2 cows were lame twice), 30 mastitis, 10 metritis, 5 ketosis, 2 colic, and 51,916 control days. Due to the low occurrence of metritis, ketosis, and colic, we focused on estrus, lameness, and mastitis. We compared days with estrus, lameness, and mastitis to each other and to control days. Only significant results $(P<$ $0.05)$ are reported.

The cows were active from 0800 to 2200 h (i.e., activity level was positive, and the activity was minimal at night). We observed 2 peaks of activity, one in the morning, around $1000 \mathrm{~h}$, and one in the afternoon, around $1700 \mathrm{~h}$ (Figure 1). These 2 peaks correspond to the cleaning of cubicles, probably inducing cows standing up. The 1700-h peak is less marked when cows are affected by lameness, mastitis, or estrus. High activity can also be observed at other times of the day, making the rhythm more erratic especially in case of lameness and mastitis.

We observed significant differences in average activity level and its variations during the day between control days and days when a specific animal state was detected by the farmer (Table 1 ). Cows were more active throughout the day and showed less marked withinday variations when estrus or mastitis was detected (d 0 ) compared with control days. In the case of estrus, we observed similar changes in activity level and its variations on $\mathrm{d}-1$ but not on $\mathrm{d}-2$, where circadian variations (measured with $\mathrm{SD}$ ) were seen to increase. In the case of mastitis, no hyperactivity was observed on $\mathrm{d}-1$ and -2 , but there was less activity variation. In the case of lameness, we observed a decrease in activity during the day but an increase at night on $\mathrm{d} 0$, whereas on $d-1$ only nocturnal activity increased; this was accompanied by a decrease in circadian variations, which was more marked on d 0 (SD and RMSSD affected) than $d-1$ (only RMSSD significantly affected).

In conclusion, the circadian organization of cow activity seems sensitive to the physiological or pathological state of the cows. Counterintuitively, diseased cows do not necessarily decrease their activity. Indeed, mastitic cows were found to be hyperactive throughout the day, whereas lame cows were found to be hyperactive at night. Other diseases may result in the opposite pattern of change. Indeed, sickness behavior often includes a reduction in activity, as observed in calves administered LPS (Borderas et al., 2008). These changes are consecutive to disease and are probably linked to some malaise or pain experienced by the animals. For instance, mastitis may make cows more reluctant to lie down due to the pain on the udder when lying (Medrano-Galarza et al., 2012; Fogsgaard et al., 2015). Alternatively, the behavioral changes may be part of the causes of a disorder. A longer amount of time spent standing by cows (vs. lying) can result in more foot or heel lesions and lameness (Galindo and Broom, 2000). According to our results, the changes in the activity level of cows experi- 


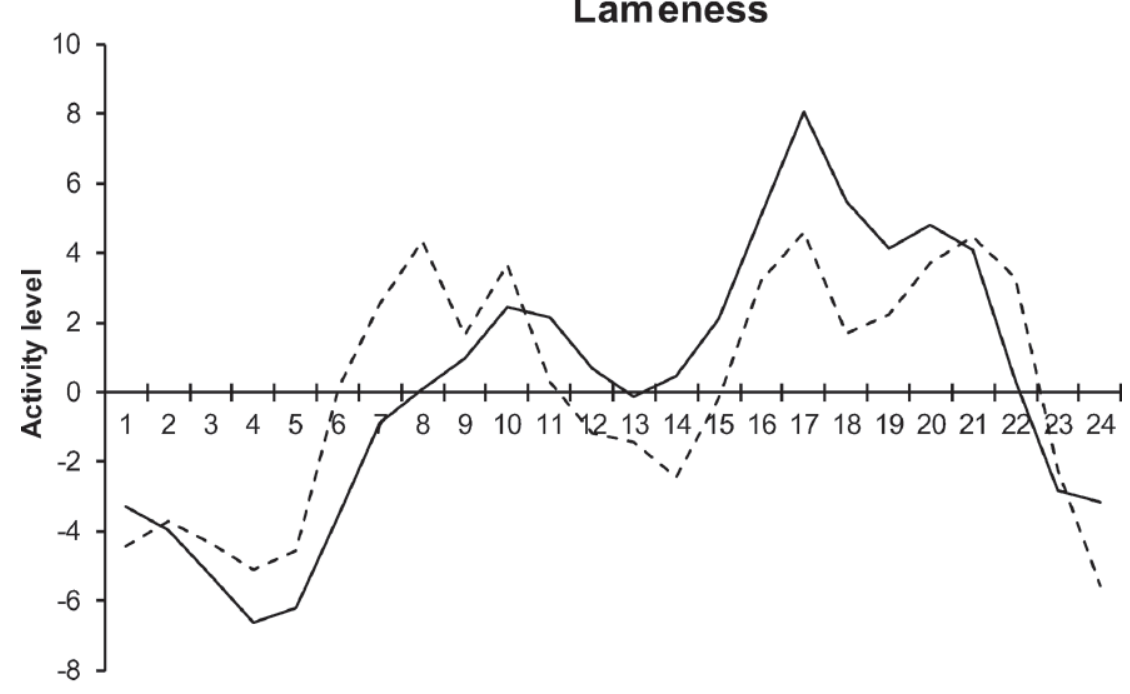

Lameness
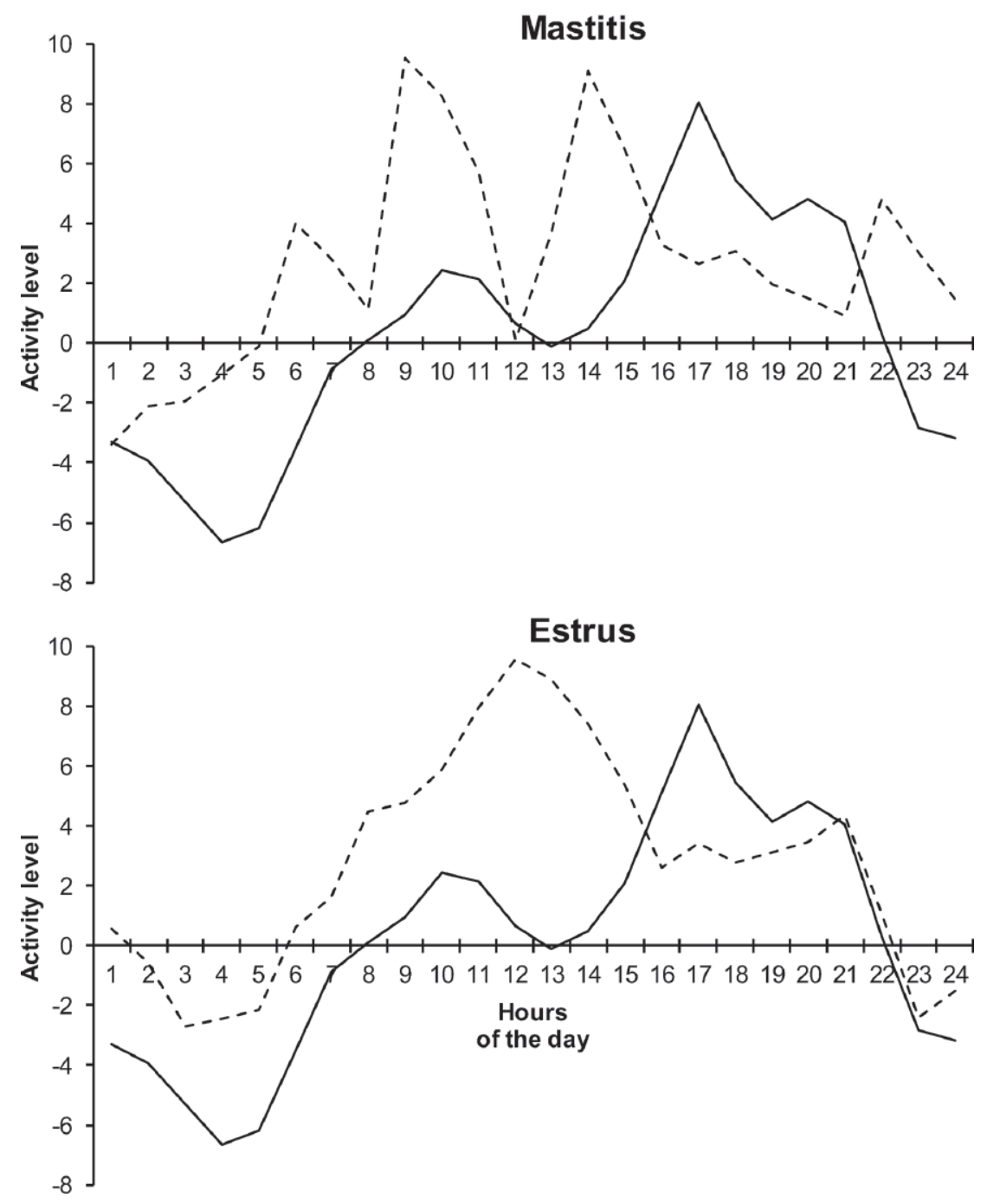

Figure 1. Circadian variations in activity level in a herd of 350 cows observed for 5 mo. Activity level is a weighted sum of the percentage time spent in the different activities, based on the following weights: resting $=-0.15$; in alley $=+0.12$; feeding $=+0.34$. On each graph, we show control days (solid line) where the cows were supposed to be neither diseased nor in estrus and days where the cows were diseased or in estrus (dashed line). 


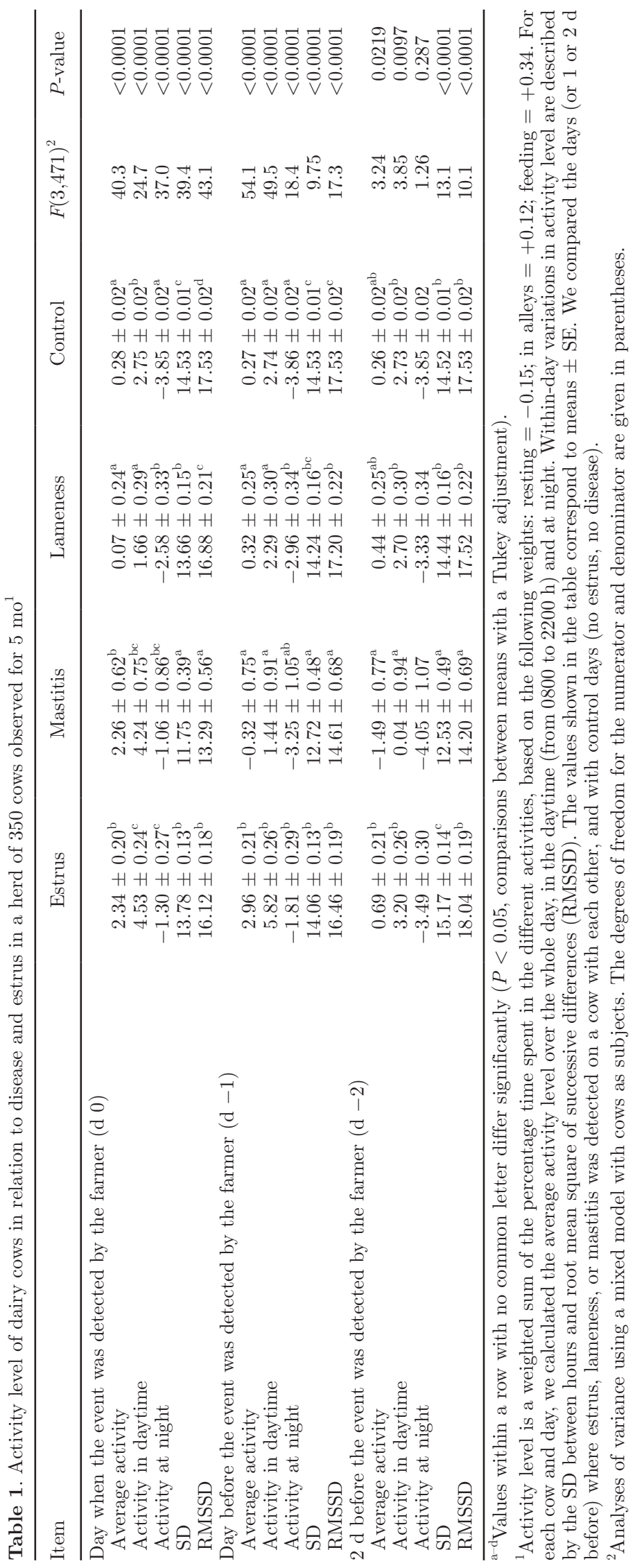


encing a disease or estrus are observed on the same day as the disorder is detected by the farmer, and thus do not serve as an advance warning.

However, the size of the circadian variations in activity (measured with SD or RMSSD) was observed to change 1 or $2 \mathrm{~d}$ before the farmer detected a disorder. These changes appear to be earlier signs of a problem than the intrinsic activity level or changes in feeding behavior that occur $1 \mathrm{~d}$ before a disorder (González et al., 2008). Furthermore, it appears to be possible to differentiate the cows' states based on the pattern of changes over time. In our study, an increase in circadian variations followed by a decrease in circadian variations accompanied by hyperactivity seemed to characterize estrus. A decrease in circadian variations (not preceded by an increase) again accompanied by hyperactivity seemed to be indicative of mastitis (if the cows showed hyperactivity over the day) or lameness (the cows showed hyperactivity only during the night period). The subtle variations observed here need to be confirmed in other settings, possibly with more systematic clinical observations of the animals and use of additional diagnosis tools, before we can start estimating the predictive value of these proposed new indicators. They nevertheless offer interesting avenues for further research to design models to predict physiological or pathological states of cows from real-time positioning.

\section{ACKNOWLEDGMENTS}

This study was part of the European project \#311825 EU-PLF (Animal and farm-centric approach to precision livestock farming in Europe) co-financed by the European Commission. We thank Auvergne Traductions Techniques for checking and amending the English writing.

\section{REFERENCES}

Borderas, T. F., A. M. de Passille, and J. Rushen. 2008. Behavior of dairy calves after a low dose of bacterial endotoxin. J. Anim. Sci. 86:2920-2927.

Coletti, C. 2015. CowView: A PLF tool to evaluate the feeding behaviour in relation to different feeding strategies. MS thesis. University of Milan, Milan, Italy.

Fogsgaard, K. K., T. W. Bennedsgaard, and M. S. Herskin. 2015. Behavioral changes in freestall-housed dairy cows with naturally occurring clinical mastitis. J. Dairy Sci. 98:1730-1738.

Foster, R. G., and L. Kreitzman. 2014. The rhythms of life: What your body clock means to you! Exp. Physiol. 99:599-606.

Galindo, F., and D. M. Broom. 2000. The relationships between social behaviour of dairy cows and the occurrence of lameness in three herds. Res. Vet. Sci. 69:75-79.

González, L. A., B. J. Tolkamp, M. P. Coffey, A. Ferret, and I. Kyriazakis. 2008. Changes in feeding behavior as possible indicators for the automatic monitoring of health disorders in dairy cows. J. Dairy Sci. 91:1017-1028.

Medrano-Galarza, C., J. Gibbons, S. Wagner, A. M. de Passille, and J. Rushen. 2012. Behavioral changes in dairy cows with mastitis. J. Dairy Sci. 95:6994-7002.

Norring, M., J. Haggman, H. Simojoki, P. Tamminen, C. Winckler, and M. Pastell. 2014. Short communication: Lameness impairs feeding behavior of dairy cows. J. Dairy Sci. 97:4317-4321.

Smolensky, M. H., R. C. Hermida, A. Reinberg, L. Sackett-Lundeen, and F. Portaluppi. 2016. Circadian disruption: New clinical perspective of disease pathology and basis for chronotherapeutic intervention. Chronobiol. Int. 33:1101-1119.

Solberg, L. C., T. H. Horton, and F. W. Turek. 1999. Circadian rhythms and depression: Effects of exercise in an animal model. Am. J. Physiol. 276:R152-R161.

Sprecher, D. J., D. E. Hostetler, and J. B. Kaneene. 1997. A lameness scoring system that uses posture and gait to predict dairy cattle reproductive performance. Theriogenology 47:1179-1187.

Stewart, K. T., A. M. Rosenwasser, H. Hauser, J. R. Volpicelli, and N. T. Adler. 1990. Circadian rhythmicity and behavioral depression: I. Effects of stress. Physiol. Behav. 48:149-155.

Task Force on HRV. 1996. Heart rate variability. Standards of measurement, physiological interpretation, and clinical use. Circulation 93:1043-1065.

Veissier, I., A. Boissy, A. M. dePassillé, J. Rushen, C. G. van Reenen, S. Roussel, S. Andanson, and P. Pradel. 2001. Calves' responses to repeated social regrouping and relocation. J. Anim. Sci. 79:25802593.

Veissier, I., P. Le Neindre, and G. Trillat. 1989. The use of circadian behaviour to measure adaptation of calves to changes in their environment. Appl. Anim. Behav. Sci. 22:1-12. 